\title{
Monte Carlo model of resistance evolution in embedded PCM with Ge-rich GST
}

\author{
O. Melnic ${ }^{1}$, M. Borghi ${ }^{2}$, E. Palumbo ${ }^{2}$, P. Zuliani ${ }^{2}$, R. Annunziata ${ }^{2}$, D. Ielmini ${ }^{1}$ \\ ${ }^{1}$ Politecnico di Milano, Milano 20133, Italy; ${ }^{2}$ STMicroelectronics, Agrate Brianza 20864, Italy; \\ Email: octavian.melnic@polimi.it
}

\begin{abstract}
This work presents an optimized model for resistance evolution in PCM cells with Ge-rich GeSbTe (GST) alloy as active material. Unlike conventional $\mathrm{Ge}_{2} \mathrm{Sb}_{2} \mathrm{Te}_{5}$, the low-resistance (set) state of Ge-rich GST shows a resistance drift to high resistance $\mathrm{R}$, similar to the high resistance (reset) state, which could be a potential risk for data reliability. We develop a Monte Carlo (MC) model which predicts the time evolution of $\mathrm{R}$ at the statistical level of a memory array at various temperature $T$. The model is validated against variable temperature annealing, such as the soldering profile in embedded PCM, supporting the good reliability of Ge-rich GST at high T.
\end{abstract}

Introduction. The phase change memory (PCM) is an attractive solution for embedded memories in automotive applications, due to its CMOS process compatibility, BEOL integration and good data retention at high temperature thanks to the optimized Ge-rich GST active material [1]. Both programmed states, namely the poly-crystalline set state and the amorphous reset state, show similar evolution, including a T-activated drift [2] according to the power law $\mathrm{R} / \mathrm{R}\left(\mathrm{t}_{0}\right)=$ $\left(\mathrm{t} / \mathrm{t}_{0}\right)^{v}$, followed by a $\mathrm{R}$ drop due to crystallization and grain growth [3]. A PCM model describing the T-activated $\mathrm{R}(\mathrm{t})$ was already been proposed [4]. However, as shown in Fig. 1, the drift and crystallization parameters, such as the initial resistance $R_{\text {prog, }}$, the drift exponent $v$ and the crystallization time $t_{x}$, show cell-to-cell variations within the array that need to be carefully taken into consideration for reliability prediction at the array/product level. This work presents a statistical MC model for $\mathrm{R}(\mathrm{t})$ evolution in PCM, validated over both isothermal and variable $\mathrm{T}$ experiments for large populations of embedded PCMs.

Experiments. A wall-type PCM in a state-of-the-art bipolarCMOS-DMOS (BCD) technology was studied in this work [1]. Fig. 2 shows the set/reset pulses and a cross section TEM of the cell in the inset. After programming at $25^{\circ} \mathrm{C}$, the cells were annealed with a sequence of high $\mathrm{T}$ bakes, followed by readout at $\mathrm{T}_{\mathrm{R}}=25^{\circ} \mathrm{C}$. Each experiment involves a population $>100$ cells for each programmed state. Fig. 3 shows the measured set-state $\mathrm{R}$ as a function of time at increasing annealing temperature $\mathrm{T}_{\mathrm{A}}$ $=125^{\circ} \mathrm{C}, 180^{\circ} \mathrm{C}$ and $220^{\circ} \mathrm{C}$. Data show $\mathrm{R}$ drift followed by crystallization and a third regime of $\mathrm{R}$ increase [4]. Note that a relatively low $\mathrm{T}_{\mathrm{A}}$ allows to accurately evaluate the drift coefficient $v$ (Fig. 1b), while a higher $\mathrm{T}_{\mathrm{A}}$ allows to extract the crystallization time $t_{x}$ (Fig. 1c) for each cell in the population. Fig. 4a shows the correlation of $v$ as a function of $R_{\text {prog }}$ for $T_{A}$ $=85^{\circ} \mathrm{C}$ and $200^{\circ} \mathrm{C}$, indicating that the drift slope increases with $\mathrm{T}_{\mathrm{A}}$. Also, $v$ increases with $\mathrm{R}_{\text {prog, }}$ as shown by $\mathrm{R}(\mathrm{t})$ of various cells and increasing $\mathrm{T}_{\mathrm{A}}$ in Fig. $4 \mathrm{~b}$.

MC model. Following [4], we describe the time evolution $\mathrm{R}(\mathrm{t})$ as a $\mathrm{T}$-activated conduction $\mathrm{R}=\mathrm{R}_{0} \exp \left(\mathrm{E}_{\mathrm{C}} / \mathrm{kT}_{\mathrm{R}}\right)$, where the activation energy for conduction $\mathrm{E}_{\mathrm{C}}$ changes with time according to [4]:
$\mathrm{E}_{\mathrm{C}}=\left\{\mathrm{E}_{\mathrm{C} 1}+\mathrm{E}_{\mathrm{C} 2}+\left[\mathrm{E}_{\mathrm{C} 2}-\mathrm{E}_{\mathrm{C} 1}\right]^{*} \tanh \left[\eta^{-1} \log \left(\tau_{0}\left(\mathrm{t}, \mathrm{T}_{\mathrm{A}}\right) / \tau_{0 \mathrm{X}}\right)\right]\right\} / 2$

$\mathrm{E}_{\mathrm{C} 1,2}=\mathrm{E}_{\mathrm{C} 01,2}+\alpha_{1,2} \mathrm{~T}_{\mathrm{R}} \mathrm{E}_{\mathrm{SR}}^{*}\left(\mathrm{t}, \mathrm{T}_{\mathrm{A}}\right)$

where $E_{S R}^{*}\left(t, T_{A}\right)$ and $\tau_{0}\left(t, T_{A}\right)$ are state variables for drift and crystallization, respectively [4], with parameters $\mathrm{T}_{\mathrm{MN}}=900 \mathrm{~K}$, $\tau_{00}=10 \mathrm{~ms}, \mathrm{E}_{\mathrm{X}, \mathrm{SET}}=2.05 \mathrm{eV}$ and $\mathrm{E}_{\mathrm{X}, \mathrm{RESET}}=2.49 \mathrm{eV} ; \eta_{\mathrm{SET}}=0.9$ and $\eta_{\text {RESET }}=0.3$. Fig. 5 shows the calculated $E_{C}$ as a function of time for the set state. The increase of $E_{C}$ can be understood by structural relaxation at the origin of drift, and fully accounts for the increase of R during drift [4]. Calculations from Eq. (1) are reported in Fig. 3, showing that the model can describe the drift and the crystallization at various $\mathrm{T}_{\mathrm{A}}$.

To develop a MC model, Eq. (1) was extended to the statistical level by accounting for the cell-to-cell variations of $R_{\text {prog }}, v$ and $t_{x}$ in Fig. 1. To this purpose, we introduced the distributions of $\mathrm{E}_{\mathrm{C} 01} \sim \operatorname{Normal}\left(\mu_{\mathrm{Ec} 01}, \sigma_{\mathrm{Ec} 01}\right)$ for $\mathrm{R}_{\mathrm{PROG}}, \alpha_{1} \sim \operatorname{Normal}\left(\mu_{\alpha 1}, \sigma_{\alpha 1}\right)$ for $v$, and $\tau_{0 \mathrm{x}} \sim \operatorname{Lognormal}\left(\mu_{\tau 0 \mathrm{x}}, \sigma_{\tau 0 \mathrm{x}}\right)$ for $\mathrm{t}_{\mathrm{x}}$. Tab. 1 shows the $\mu$ and $\sigma$ for distributions in both states. A correlation coefficient $\rho=0.8$ was used for $\mathrm{E}_{\mathrm{C} 01}$ and $\alpha_{1}$ according to data in Fig. 4.

Results and discussion. Fig. 6 shows the measured and calculated $\mathrm{R}(\mathrm{t})$ at increasing $\mathrm{T}_{\mathrm{A}}=180^{\circ} \mathrm{C}$ for various cells in the set state, indicating excellent accuracy in the statistical population. Fig. 7 shows the distributions of measured and calculated $\mathrm{R}$ at increasing time for the set state at $180^{\circ} \mathrm{C}$ (a) and the reset state at $220^{\circ} \mathrm{C} \mathrm{(b).} \mathrm{Both} \mathrm{the} \mathrm{median} \mathrm{values} \mathrm{and} \mathrm{the}$ distribution shape are accurately described by the $\mathrm{MC}$ model. Fig. 8 shows the correlation $\mathrm{v}\left(\mathrm{R}_{\text {prog }}\right)$ at $\mathrm{T}_{\mathrm{A}}=85^{\circ} \mathrm{C}$ and $200^{\circ} \mathrm{C}$ (a) and $v$ as a function of $\mathrm{T}_{\mathrm{A}}$ (b), highlighting the statistical accuracy of the MC model.

The MC model was then tested against multi-T experiments, consisting of a sequence of $1 \mathrm{hr}$-bakes at increasing $\mathrm{T}_{\mathrm{A}}$. Fig. 9 shows the measured and calculated $\mathrm{R}$ for set (a) and reset states (b). Fig. 10 shows $\mathrm{R}$ for annealing at $85^{\circ} \mathrm{C}$ for $1400 \mathrm{hr}$, followed by a bake at $160^{\circ} \mathrm{C}$. The transient behaviour is well captured by the model, for both the median value (a) and the distribution shape (b). The ability to describe variable-T regimes is further supported by Fig. 11, showing $\mathrm{R}(\mathrm{t})$ for set and reset states before/after a soldering reflow experiment reaching $260^{\circ} \mathrm{C}$ for $\approx 40$ seconds (see inset). The results support the MC model for reliability prediction and qualification of embedded PCM.

Conclusions. We developed a comprehensive MC simulation platform for the time evolution of PCM cells, describing drift and crystallization in the set and reset states at variable $\mathrm{T}$ with statistical accuracy. The model provides a valuable tool for reliability prediction and product qualification of embedded PCM devices.

\section{References}

[1] P. Zuliani et al., Solid-State Electronics 111, 27 (2015)

[2] D. Ielmini et al., Applied Physics Letters 92, 193511 (2008)

[3] M. Salinga et al., Nature Communications, 4 (2013)

[4] N. Ciocchini et al., IEEE Trans. Electron Devices 612136 (2014) 


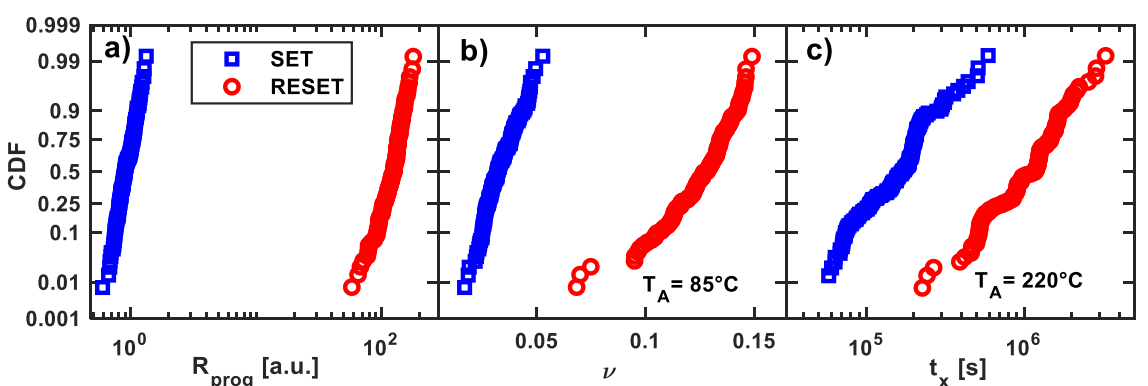

Fig.1 Measured distributions: a) programmed resistance, b) drift coefficient $v$, and c) crystallization time $t_{x}$.

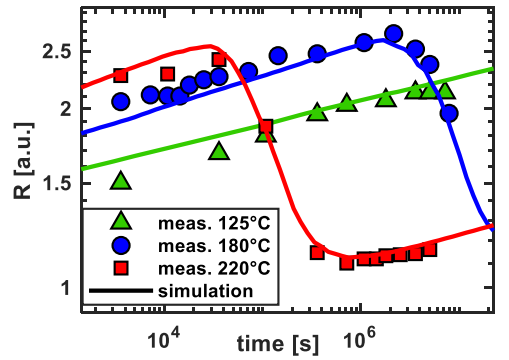

Fig. 3 Measured/simulated $R(t)$ of a PCM cell in the SET state.

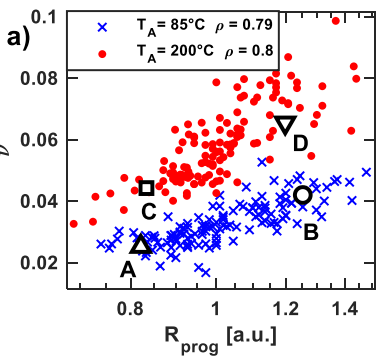

Fig.4 a) Experimental $v\left(R_{\text {prog }}\right)$. Both datasets have a high correlation coefficient $\rho$. b) $R(t)$ examples, at $85^{\circ} \mathrm{C}(\mathrm{A}, \mathrm{B})$ and $200^{\circ} \mathrm{C}(\mathrm{C}, \mathrm{D})$.

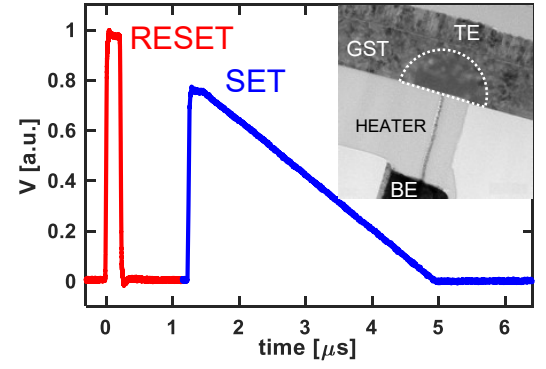

Fig.2 Program pulses. Inset: TEM image of the PCM cell.

Tab.1 Monte Carlo simulation parameters.

Fig.6 Examples of measured

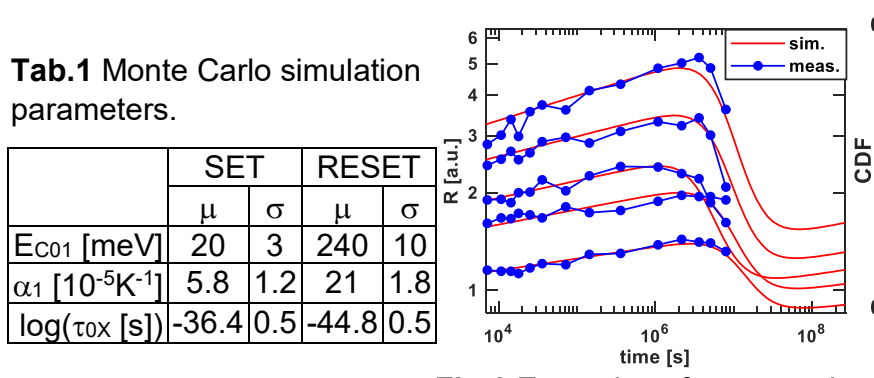

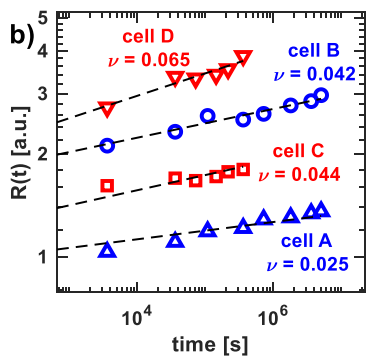

Fig. 5 Example of a single cell $\mathrm{E}_{\mathrm{c}}(\mathrm{t})$ in the SET state, according to (1).

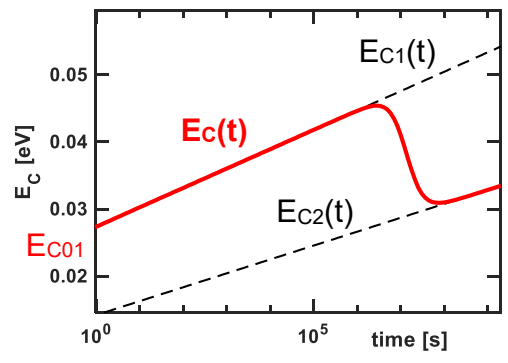

and simulated $\operatorname{RSET}_{\mathrm{SE}}(\mathrm{t})$ at $180^{\circ} \mathrm{C}$
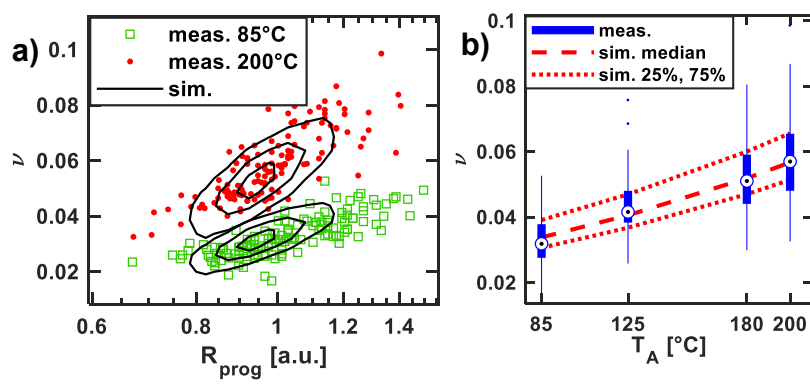

Fig.8 a) Scatter plot of experimental $v$ (RPROG), and the contour plots of simulation bivariate distributions, at 0.2 , 0.5 and 0.8 from mode. b) Box plot of experimental $v\left(T_{A}\right)$ and quartiles of the simulated distributions.
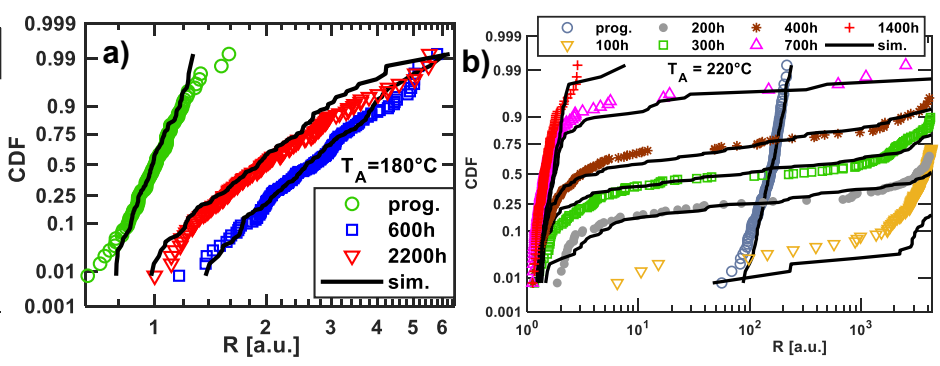

Fig.7 a) RSET and b) RRESET distributions during isothermal bakes.
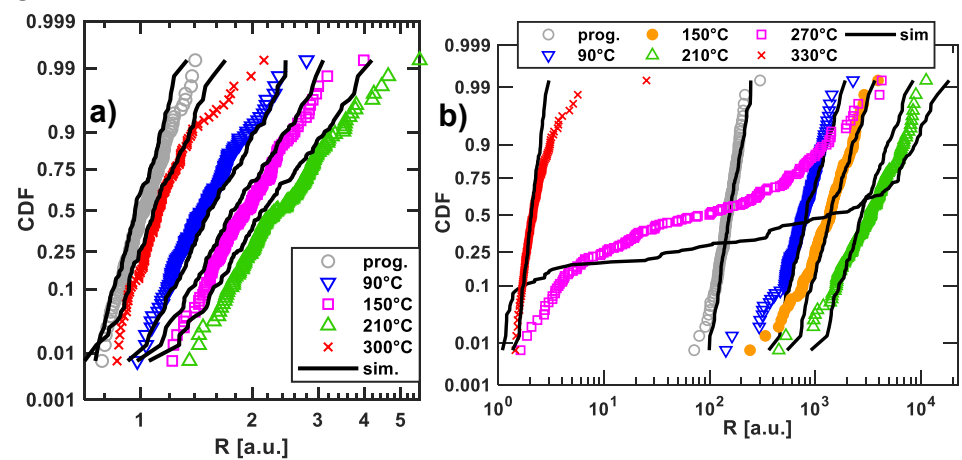

Fig.9 a) RSET and b) R RESET after consecutive bakes of $1 \mathrm{~h}$ each at rising temperatures.
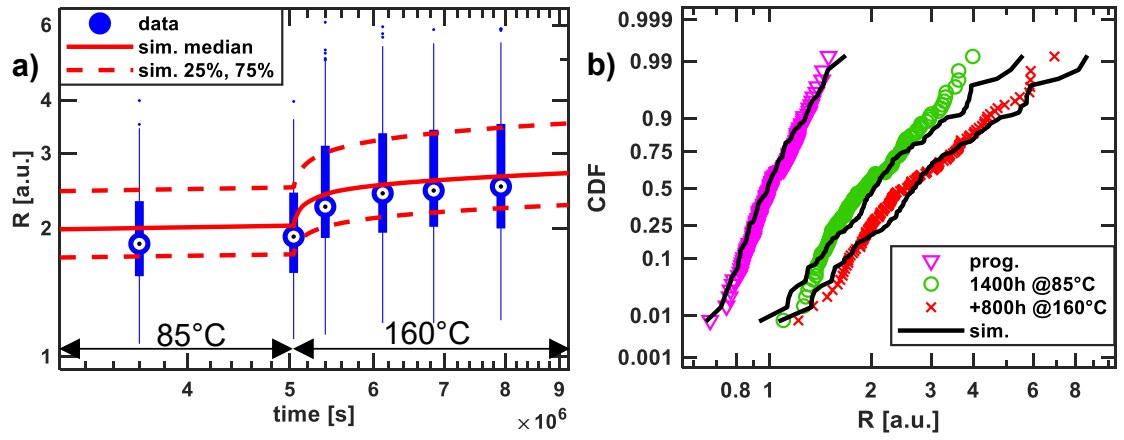

Fig.10 a) Resistance transition between isothermal regimes $85^{\circ} \mathrm{C}$ and $160^{\circ} \mathrm{C}$ b) Resistance distributions at the last measured point for each temperature.

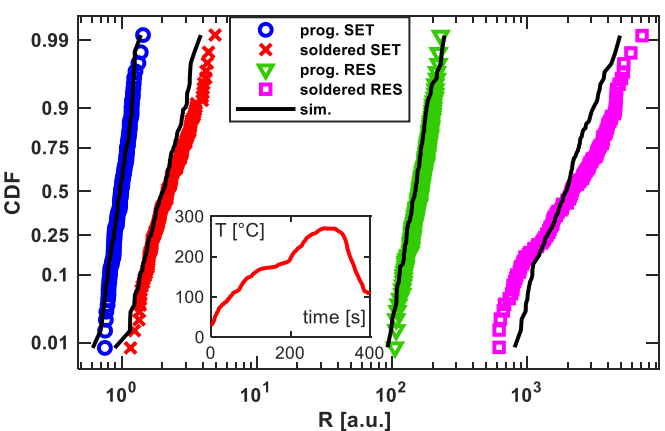

Fig.11 SET/RESET distributions before and after soldering $T$ profile (inset) is applied. 